\title{
Matemática, linguagem e formação do professor
}

\author{
Mathematics, language and teacher education
}

\author{
Silvia Regina Vieira da Silva ${ }^{1}$ \\ Ângela Coletto Morales Escolano²
}

\section{Resumo}

Neste ensaio, fundamentado na teoria sociointeracionista de Vygotsky e nos princípios da pesquisa qualitativa, discute-se a importância da aquisição de conceitos matemáticos no processo de desenvolvimento cognitivo no ambiente escolar, por meio do qual a linguagem matemática, especificamente, é relevante. Para tanto, serão compartilhadas narrativas de docentes e discentes que fazem parte do curso de licenciatura em Matemática, pois a construção das mesmas possibilita uma ressignificação da escola, evidenciando emoções e razões. Discute-se, ainda, a importância do professor, enquanto mediador no processo de ensino e de aprendizagem, e as dificuldades enfrentadas pelo mesmo para que isto aconteça. Para tanto é importante buscar a quebra na reprodução dos modelos didáticos internalizados ao longo do tempo, sendo este um desafio a ser enfrentado por todos os professores, porque é comum o professor formador apresentar métodos didáticos diferenciados e a sua prática não se constituir como um exemplo a ser seguido. Assim, não é rompido o ciclo de reprodução de modelos vivenciados que, muitas vezes, são do século XIX, apesar da produção científica a respeito e dos projetos de formação continuada.

Palavras-chave: Linguagem matemática. Formação de conceitos. Ensino de matemática.

\section{Abstract}

On this essay, based on Vygotsky's socio-interactionist theory and on the principles of qualitative research, it is discussed the importance of mathematical concepts acquisition on the cognitive development process in the school environment, through which the mathematical language, specifically, is relevant. Therefore, narratives of professors and students

\footnotetext{
${ }^{1}$ Doutora em Educação Matemática pela UNESP/Rio Claro. Professor Assistente Doutor da Universidade Estadual Paulista Júlio de Mesquita Filho, Brasil. E-mail: silviaregina@mat.feis.unesp.br.

2 Doutora em Psicologia pela Universidade de São Paulo, Brasil. Professor Assistente Doutor da Universidade Estadual Paulista Júlio de Mesquita Filho, Brasil. E-mail: angelcme@bio.feis.unesp.br
} 
from the Mathematics degree course will be shared, because their building makes possible the school resignification, evidencing emotions and reasons. It is also discussed the importance of the professor, as a mediator in the teaching and learning process, and the difficulties faced by the professor to make it happen. Therefore, it is important to search for a break in the reproduction of didactic models internalized throughout time, this is a challenge to be faced by all professor, because it is common for a professor to present differentiated teaching methods and their practice does not constitute an example to be followed. This way, the cycle of experienced models that, many times, come from the XIX century, in spite of the scientific production about it and the continuing education projects, is not broken.

Key-words: Mathematics language. Concepts formation. Mathematics teaching.

\section{Introdução}

Neste texto pretende-se discutir a importância da aquisição de conceitos matemáticos no processo de desenvolvimento cognitivo, segundo princípios preconizados por Vygotsky, no qual a linguagem matemática, especificamente, é de extrema relevância.

Para tanto serão utilizadas experiências vivenciadas por docentes do ensino superior que ministram aulas no curso de Licenciatura em Matemática.

\subsection{Um pouco de teoria}

O que é linguagem?

Se a internet for utilizada como primeiro recurso para reflexão sobre tal pergunta pode-se encontrar que linguagem é: "Faculdade que tem todo homem de comunicar seus pensamentos e sentimentos; Conjunto de sinais falados, escritos ou gesticulados de que se serve o homem para exprimir esses pensamentos e sentimentos; Faculdade inata de toda a espécie humana de expressão audivel e articulada, produzida pela ação de língua e dos órgãos vocais adjacentes (...); Sistema de comunicação animal por meio de sons, cantos e outros meios: Alguns 
estudos indicam que os golfinhos e as baleias têm linguagem própria. $(\ldots)^{\prime 3}$

Ou ainda: "Linguagem pode se referir tanto à capacidade especificamente humana para aquisição e utilização de sistemas complexos de comunicação, quanto a uma instância específica de um sistema de comunicação complexo". 4

Portanto, as pessoas que buscam tal informação desta forma podem associar linguagem, no primeiro caso, à simples decodificação de um código de comunicação. Já no segundo caso, é enfatizada a capacidade humana de comunicação, desconsiderando a capacidade dos animais de se comunicarem.

Para a filósofa Marilena Chauí (2000) "a linguagem é um sistema de signos ou sinais usados para indicar coisas, para a comunicação entre pessoas e para a expressão de ideias, valores e sentimentos" (p.177).

Mas, se alguém realizar um estudo científico sobre a temática poderá encontrar diversas abordagens, como a behaviorista, a interacionista, a sociointeracionista, dentre outras. E, respectivamente, diversos representantes: Skinner, Piaget, Vygostky ${ }^{5}$.

Este texto fundamenta-se na teoria sociointeracionista por meio de Vygotsky (1991), que entende a linguagem humana como um sistema interativo entre sujeito e objeto que, por meio do simbolismo, tem como funções o intercâmbio social e o pensamento generalizante. E o contexto cultural, que media o processo de aprendizagem, faz com que a

3 LINGUAGEM. In: MICHAELIS, Dicionário Brasileiro da Língua Portuguesa. Saõ Paulo: Editora Melhoramentos Ltda. Disponivel em: http://michaelis.uol.com.br/modernoportugues/busca/portugues-brasileiro/LINGUAGEM/. Acesso em: 28 fev. 2018.

4 LINGUAGEM. In: WIKIPÉDIA, a enciclopédia livre. Flórida: Wikimedia Foundation, 2018. Disponivel em:

$<$ https://pt.wikipedia.org/w/index.php?title=Linguagem\&oldid=51386482>. Acesso em: 28 fev. 2018.

5 A escrita do nome deste teórico apresenta variações. Aqui será utilizada Vygotsky, como aparece nas fontes consultadas. 
linguagem assuma papel de suma importância na formação das generalizações, imprescindível para a formação de conceitos. Oliveira (1992), ao analisar a função da linguagem a luz das teorizações de Vygostky, endossa tais afirmações quando discute que: "a linguagem simplifica e generaliza a experiência, ordenando as instâncias do mundo real em categorias conceituais cujo significado é compartilhado pelos usuários dessa linguagem" (OLIVEIRA, 1992, p. 23).

Lev Semyonovich Vygotsky nasceu em 1896 na cidade de Orsha, na Rússia, e morreu em Moscou no ano de 1934, com apenas 38 anos. Foi um psicólogo russo que desenvolveu a Psicologia Histórico Cultural, na qual entende o ser humano e seu desenvolvimento por meio da perspectiva sociocultural ou sociointeracionista, buscando o desenvolvimento das funções psicológicas superiores, contrapondo-se a teoria baseada no estímulo resposta.

Por sua vez, dentro da perspectiva sociocultural, a interação social pode ser entendida, como um suporte para a promoção do desenvolvimento humano (CUNHA; ENUMO; CANAL, 2006), pois, é por meio dela que o sujeito obtém instrumentos culturais (TASSONI, 2000) e, consequentemente, pode ter seu lugar nas relações humanas alteradas (VYGOTSKY, 1988; 1991; VYGOTSKY; LURIA; LEONTIEV, 1988).

Vale ressaltar que a linguagem é de essencial importância na formação de conceitos que por sua vez são construções culturais internalizadas pelos sujeitos ao longo de seu desenvolvimento (OLIVEIRA, 1992; DE LIMA DIAS, 2014). Não sendo um comportamento inato, a formação de conceitos se dá por meio da mediação entre os pares e sempre se delimita pelo que é valorizado culturalmente para determinado grupo social (VYGOTSKY, 1988), sendo resultado de uma atividade complexa em que todas as funções intelectuais básicas são utilizadas (VYGOTSKY, 1991). 
Especificamente sobre a linguagem matemática Da Silveira (2010) destaca que esta, "se desenvolve na escrita e é uma construção subjetiva, já que deriva da intersubjetividade e se objetiva por meio de símbolos" (p.85). Ou seja, a fala não é "necessariamente exata", podendo dar muitos significados e variações ao que tenta conceituar. Já a escrita necessita de mais objetividade para que a comunicação seja estabelecida. Por exemplo, considere o quadrado, uma figura geométrica regular de quatro lados. Quando a definição de tal figura é apresentada a uma criança, a mesma, antes de ter acesso ao formalismo matemático, se refere ao vértice como: ponta, bico, canto. Daí o professor, objetivamente, apresenta a forma como tal objeto matemático é nomeado.

Já Lorensatti (2009) afirma que, tratando-se de um sistema simbólico, a linguagem matemática necessita de um rigor quanto ao uso de símbolos, mas a apropriação deste conhecimento é mediado pelas linguagens (natural e matemática).

Por sua vez, a formação de conceitos exige que o sujeito abstraia os aspectos fundamentais de determinada situação, caracterizando, assim, uma operação mental (SFORNI, 2004; MOYSES, 2014), que perpassa a interação com os pares e é mediada por instrumentos e sistemas simbólicos. Para Chauí (2000), conceito ou ideia oferece o significado ou essência de alguma coisa, "sua origem ou causa, suas consequências ou seus efeitos, seu modo de ser e de agir" (p.198).

De modo geral, os conceitos podem ser divididos em conceitos espontâneos e conceitos científicos, dependendo do contexto no qual estão inseridos e compreendendo-os como instrumentos psicológicos. A apropriação dos mesmos não pode ser entendida como mera definição e/ou memorização de características do objeto e implicam atitudes distintas em relação a ele. E, no que diz respeito às diferenças entre as conceituações mencionadas, conceitos espontâneos são desenvolvidos nas situações cotidianas de utilização da linguagem, os científicos são 
elaborados por meio das mediações sistematizadas (GÓES; CRUZ, 2006; MARTINS, 2013).

Ainda sobre a formação de conceitos Martins (2013) destaca que os conceitos científicos:

[...] formam-se na tensão problematizadora de uma vasta gama de atividades que colocam o pensamento em curso, daí que o seu ensino não se identifique com ações casuais e assistemáticas, mas com ações didáticas específicas. A formação dos conceitos científicos exige e se articula a uma série de funções psíquicas, a exemplo da percepção complexa, da atenção voluntária, da memória lógica e, sobretudo das operações lógicas do raciocínio, isto é, da análise, síntese, comparação, generalização e abstração. (MARTINS, 2013, p. 140).

Partindo do pressuposto que a escola tem por responsabilidade promover por meio do ensino, a formação e o desenvolvimento de conceitos, procedimentos e atitudes, tarefas que, mesmo complementares, estão carregadas de complexidade quanto aos seus aspectos epistemológicos, metodológicos e socioculturais específicos, esta instituição torna-se capaz de fazer a mediação entre os conceitos cotidianos e os científicos (MORAIS, 2009; DE AZEVÊDO; DO RÊGO, 2016).

E, mais especificamente em relação ao ensino de Matemática:

A Matemática, por sua universalidade de quantificação e expressão, como linguagem, portanto, ocupa uma posição singular. No Ensino Médio, quando nas ciências torna-se essencial uma construção abstrata mais elaborada, os instrumentos matemáticos são especialmente importantes. Mas não é só nesse sentido que a Matemática é fundamental. Possivelmente, não existe nenhuma atividade da vida contemporânea, da música à informática, do comércio à meteorologia, da medicina à cartografia, das engenharias às comunicações, em que a Matemática não compareça de maneira insubstituivel para codificar, ordenar, quantificar e interpretar compassos, taxas, dosagens, coordenadas, tensões, frequências e quantas outras variáveis houver. A Matemática ciência, com seus processos de construção e validação de conceitos e argumentações e os procedimentos de generalizar, relacionar e concluir que lhe são característicos, permite estabelecer relações e interpretar fenômenos e informações. As formas de pensar 
dessa ciência possibilitam ir além da descrição da realidade e da elaboração de modelos. (BRASIL, 2000, p. 09)

E, segundo Miguel (2011), a Matemática escolar, como um processo de formação de conceitos, exige repensar o papel do professor e sua inserção no contexto escolar, relacionando o processo de conscientização do professor e a necessidade de uma nova postura diante do aluno. $\mathrm{O}$ "[...] processo significativo de ensino de Matemática deve conduzir os alunos à exploração de uma grande variedade de ideias e de estabelecimento de relações entre fatos e conceitos" (p. 377). Mas ainda é preciso avançar no sentido de conduzir as crianças a perceberem a evolução das ideias matemáticas, ampliando progressivamente a compreensão que delas se tem (MIGUEL, 2011).

Morais (2009), em conformidade com a última citação, afirma que o professor tem importância fundamental, pois cabe a ele a tarefa de organizar o ensino de forma a criar sentido para seus alunos favorecendo a apropriação de conhecimentos. Portanto, o professor de matemática, por meio da linguagem matemática, deveria assumir a responsabilidade de mediar o processo de aprendizado de conteúdos matemáticos por meio de diversas formas que se distanciassem da simples repetição e, consequente, memorização de definições.

\section{O que são números?}

Utilizando novamente a internet como primeiro recurso para uma reflexão sobre a pergunta pode-se encontrar que número é: "Cada elemento ou um conjunto de elementos do sistema numérico usado em contagem ou medição; Expressão de quantidade; [...] Categoria gramatical indicativa do número (singular ou plural) de substantivos, 
adjetivos, pronomes, artigos e verbos; [...] Classe ou categoria com certa unidade $[\ldots] . . " 6$

A linguagem matemática inclui vários termos relacionados ao sistema numérico: número, numeral, algarismo.

Número, em geral, está relacionado à quantidade e é utilizado para contar (um, dois, três, ...), ordenar (primeiro, segundo, terceiro, ...) e medir (quilômetro, quilograma, litro, ...). Numeral é a representação do número e, por sua vez, algarismo é o símbolo utilizado para formar o numeral. Por exemplo, o número quatro, no sistema romano, pode ser representado pelo numeral "IV", no sistema indo arábico pelo numeral "4", ou ainda, no sistema Maia pelo numeral

Além disso, o número teve grande destaque quando os filósofos tentavam caracterizar Ciência. Segundo Caraça (1998), alguns, tentando compreender os fenômenos da natureza, diziam que tudo era água (Tales de Mileto), outros filósofos afirmavam que tudo era ar (Anaxímenes de Mileto), desta forma, os jônicos fundamentavam a existência de uma substância primordial permanente. Posteriormente, Heráclito de Éfeso, acreditava que a existência estava associada à mudança; "a harmonia não resulta da junção de coisas semelhantes, mas da luta dos contrários" (p. 66).

Já Pitágoras acreditava que tudo era número tendo conseguido representar diversos fenômenos por meio deles; notas musicais, inclusive. O problema surgiu quando não conseguiu representar uma quantia dita incomensurável: a diagonal de um quadrado. Vale ressaltar que Pitágoras foi responsável pelas ternas pitagóricas, ou seja, a combinação de três números inteiros que satisfazem a expressão $a^{2}+b^{2}$ $=c^{2}$ relacionada a um triângulo retângulo. O conhecido Teorema de

6 NÚMERO. In: MICHAELIS, Dicionário Brasileiro da Língua Portuguesa. São Paulo: Editora Melhoramentos Ltda. Disponivel em: <http://michaelis.uol.com.br/modernoportugues/busca/portugues-brasileiro/número>. Acesso em: 28 fev. 2018. 
Pitágoras, apesar de levar o nome do filósofo, não foi demonstrado pelo mesmo, pois ele ainda não conhecia o conceito da raiz quadrada.

Mas, qual(is) o(s) conceito(s) inserido(s) na caracterização de um número? Ou melhor, o que seria necessário para que os alunos desenvolvessem a capacidade de entendimento do que é um número?

Segundo Rangel (1992) citado por Nogueira (2011):

Ao analisarmos as ações que a criança precisa desenvolver para contar objetos fica evidente que o número resulta da síntese original da classificação e da seriação(...):

- Juntar os objetos que serão contados, separação dos que não serão contados, (classificação);

. Ordenar os objetos para que todos sejam contados e somente uma vez (seriação);

- Ordenar os nomes aprendidos para a enumeração dos objetos, utilizando-os na sucessão convencional, não esquecendo nomes e nem empregando o mesmo nome mais de uma vez;

- Estabelecer a correspondência biunívoca e recíproca nomeobjeto; e finalmente;

. Entender que a quantidade total de elementos de uma coleção pode ser por um único nome.

Assim contar é estabelecer a correspondência biunívoca termo a termo, entre quatro tipos de elementos: os objetos, os gestos, o olhar, as palavras-número. (p.112)

Assim que as etapas relacionadas ao desenvolvimento dos conceitos associados a número são cumpridas o professor inicia o tratamento das quatro operações.

\subsection{Narrativa de experiências}

Neste item, fundamentando-se nos princípios da Pesquisa Qualitativa (BOGDAN; BIKLEN, 1994) serão narradas vivências que motivaram o desenvolvimento deste ensaio.

Ressaltando que as narrativas tem-se mostrado um instrumento de registro muito importante quando se tem por objetivo apreender e refletir sobre experiências vivenciadas.

O aspecto principal da abordagem sociocultural por meio da narrativa está na compreensão de que se está vivendo em um contínuo contexto experiencial, social e cultural, pois ao mesmo 
tempo em que contamos nossas histórias, refletimos sobre nossas vivências, explicitando a todos nossos pensamentos, através de nossas vozes (BOLZAN, 2002, p. 75).

Além disso, a narrativa constitui-se numa forma de aprendizado, pois, ao falar (ou ouvir) sobre nossas vivências, damos sentido às nossas práticas pedagógicas (CLANDININ, 1993). E, segundo Freitas e Fiorentini

[...] o professor, ao narrar de maneira reflexiva suas experiências aos outros, aprende e ensina. Aprende, porque, ao narrar, organiza suas idéias, sistematiza suas experiências, produz sentido a elas e, portanto, novos aprendizados para si. Ensina, porque o outro, diante das narrativas e dos saberes de experiências do colega, pode (re)significar seus próprios saberes e experiências (FREITAS; FIORENTINI, 2007, p. 66).

A escola, nesse caso, passa a ser entendida como um lócus de formação e a produção de narrativas como uma forma de reflexão e de organização da experiência.

A construção das narrativas, portanto, possibilita uma ressignificação da escola, da identidade docente, e coloca em evidência, emoções e razões.

\subsubsection{Experiências}

O desenvolvimento de projetos de formação continuada com professores que ministravam aulas de Matemática nos anos finais do Ensino Fundamental e Ensino Médio motivou estudos relacionados às quatro operações fundamentais. Por quê? Porque durante o desenvolvimento de tais cursos foi possivel ter acesso a um discurso recorrente: os alunos não conseguem compreender conceitos novos porque não têm dominio sobre as quatro operações, que deveriam ter aprendido nos primeiros anos do Ensino Fundamental. E, na época, como os professores que participavam do projeto não sabiam como o tema era abordado na etapa anterior, afirmavam não saber como sanar as dificuldades apresentadas. Então, visando oferecer um encaminhamento 
desta dificuldade, foi criado um grupo de estudos sobre a temática, no qual foi discutida a forma como era realizado o ensino das quatro operações nos primeiros anos do Ensino Fundamental.

Tal experiência motivou uma mudança no desenvolvimento da disciplina Prática de Ensino de Matemática com Estágio Supervisionado, ministrada no curso de Licenciatura em Matemática, pois, talvez, os futuros professores também necessitassem desse aprendizado para tratar possiveis dificuldades dos alunos.

$\mathrm{Na}$ primeira turma os alunos foram divididos em grupos e cada um abordou uma operação; simularam ensinar crianças dos anos iniciais do Ensino Fundamental.

Logo após as apresentações, nas quais foi possivel presenciar a satisfação dos alunos ao compreenderem o que fundamentava a técnica que utilizavam para efetivar contas, um dos alunos, apresentou uma "pesquisa" que tinha realizado. Primeiro o mesmo elaborou alguns exercícios relacionados às quatro operações; a saber, "Efetue as seguintes operações: 437:4, $375 \times 26,208$ + 153. Descreva, por extenso, as passagens usadas e, se possivel explique." Depois solicitou a resolução para sete pessoas próximas: duas pedagogas e cinco alunos que moravam na Moradia Universitária, mas não cursavam Licenciatura em Matemática. E, para surpresa dele, somente uma pessoa ficou próxima do que se esperava - um entregou a folha somente com as marcas das tentativas e o restante apenas descreveu em palavras a técnica, sem justificar.

Nos anos seguintes, a forma de abordar o tema foi sendo alterada. Por exemplo, uma vez, antes da apresentação, os alunos foram submetidos a um teste diagnóstico visando verificar se os mesmos tinham domínio da técnica que desenvolviam para efetivar as operações fundamentais. Noutro os alunos, novamente antes das apresentações, receberam contas desenvolvidas por crianças que tinham dificuldades e, 
consequentemente, erravam o resultado final. O desafio inicial dos alunos da graduação foi avaliar o erro cometido, verificar qual conceito deveria ser retomado.

Mas, foi durante o desenvolvimento das atividades de um subprojeto do PIBID/UNESP, vinculado a uma escola pública de Ensino Médio de Ilha Solteira, que surgiu a oportunidade de um trabalho diferenciado.

O referido subprojeto teve início em 2014 e, antes dos alunos iniciarem ações na escola foi realizado um estudo sobre as orientações curriculares oficiais disponiveis na época. No ano, sem um levantamento sistemático, foi observado que os alunos apresentavam dificuldades com as quatro operações. Então, os alunos/bolsistas/PIBID realizaram um estudo relacionado ao tema (conteúdo e método) para tentarem minimizar, individualmente, as dificuldades detectadas. Mas, a falta de interesse foi um fator que impressionou os alunos/bolsistas.

Durante a aula uma aluna me perguntou: 'Para quê vou precisar disso para a minha vida?'. E eu respondi: 'Você não vai fazer uma faculdade? Como você vai passar no vestibular?'. E ela respondeu: 'Vou sim, mas eu chuto todas as questões'. Quando ela respondeu isso, fiquei chocado com o desinteresse dela. (Trecho da narrativa ${ }^{7}$ do aluno/bolsista A)

Tudo isso, me fez refletir sobre como podemos fazer com que os alunos se interessem mais pelas aulas. Às vezes, me parece que o professor não tem mais só o papel de ensinar, mas ele também tem que tentar fazer com que os alunos queiram aprender, pois muitos estão ali por outros motivos que não necessariamente estudar. Em alguns momentos o professor tem que deixar de ensinar para chamar atenção e dar lição de moral, ou até mesmo exigir respeito de alguns alunos. Pelo que tenho observado isso, sem dúvida, atrapalha os alunos que estão interessados na matéria. (Trecho da narrativa da aluna/bolsista B)

7. Vale ressaltar que os alunos/bolsistas, dentre as ações programadas, escreviam narrativas relacionadas às vivências na escola. $\mathrm{E}$, neste texto, tais alunos não serão identificados. 
Então, um desafio a ser enfrentado numa próxima vez, seria incluir algo que despertasse nos alunos a importância do estudo e, em especial, o da Matemática.

Portanto, no ano seguinte, primeiramente, foi elaborada uma lista de exercícios visando detectar as dificuldades dos alunos da escola parceira do PIBID no que diz respeito às quatro operações. Em paralelo, visando propor uma reflexão sobre a importância da Matemática, foi exibido, depois de um planejamento minucioso, o filme "O Jogo da Imitação". Na sequência, depois de uma análise qualitativa das respostas (lista de exercícios) - que indicou maior dificuldade com as operações de multiplicação e divisão - o assunto foi abordado por meio de resolução de problemas e jogos; ambos em grupo. Nas narrativas dos alunos/bolsistas teve destaque a aplicação do jogo e a exibição do filme.

Os alunos tiveram algumas dificuldades no inicio (entender o jogo), mas logo passou. Percebi que, no geral, os alunos se limitavam a somar e subtrair, nunca arriscando fazer uma multiplicação ou divisão para obter o número específico proposto no jogo. Só faziam essas operações quando eu, ou a professora supervisora, estava perto, buscando certificação de que tinha feito corretamente. (Trecho da narrativa do aluno/bolsista C)

Após o anúncio do filme os alunos ficaram empolgados em ter algo diferente na escola. E após o filme, enquanto faziam atividades, perguntaram-me sobre alguns assuntos de Matemática relacionados ao filme. (Trecho da narrativa do aluno/bolsista D)

Essa foi uma atividade prazerosa, pois os alunos tiveram um bom comportamento durante a apresentação e fizeram bons textos relatando o que viram de matemática no contexto do filme e sobre a importância da mesma na história da humanidade. (Trecho da narrativa do aluno/bolsista E)

Após a finalização das intervenções foram utilizados exercícios da primeira lista, relacionados às operações de multiplicação e divisão, e foi 
observada uma pequena evolução. Seria inocência acreditar que algumas ações seriam suficientes para reverter anos de dificuldades escolares. Mas, em contrapartida, os alunos/bolsistas aprenderam muito.

Aprendi a elaborar uma avaliação diagnóstica na qual você precisa ter claros os objetivos e metas a serem atingidos na série atual e levantar quais os pré-requisitos que o aluno já deve ter adquirido na série anterior. A correção foi feita questão por questão. Uma experiência única, na qual foi possivel identificar os aspectos fortes e fracos de cada aluno. (Trecho da narrativa da aluna/bolsista F)

Ao corrigir as avaliações, fiquei decepcionado com os erros dos alunos, mas, ao mesmo tempo, contribuiu para a minha formação docente. (Trecho da narrativa do aluno/bolsista A)

\section{Discussão}

Antes de iniciar a discussão do problema (a saber: a importância dos conceitos matemáticos), vale ressaltar que, segundo documentos oficiais, ao contrário do que afirmam alguns, a finalização do processo de ensino das operações matemáticas fundamentais (adição, subtração, multiplicação e divisão) é responsabilidade do professor dos anos finais do Ensino Fundamental.

[...] os alunos devem ser estimulados a aperfeiçoar seus procedimentos de cálculo aritmético, seja ele exato ou aproximado, mental ou escrito, desenvolvido a partir de procedimentos não-convencionais ou convencionais, com ou sem uso de calculadoras. Certamente, eles ainda não têm dominio total de algumas técnicas operatórias, como da multiplicação e da divisão envolvendo números naturais, compostos de várias ordens, ou aquelas com números decimais, e isso precisa ser trabalhado sistematicamente. (BRASIL, 1998, p. 67).

Não acatar tal sugestão pode implicar no comprometimento da formação do aluno em relação a conteúdos importantes para o exercício da cidadania; outra prerrogativa de documentos oficiais. Kistermann Jr e Lins (2014) reforçam tal afirmação quando, ao "investigar a dinâmica dos 
processos de produção de significados e tomadas de decisão de individuos-consumidores, buscando compreender como estes sujeitos, situados numa sociedade líquido-moderna, tomam essas decisões referentes ao consumo" (p. 1305), indicam "entre outros resultados [...] que, independente da formação escolar, os indivíduos-consumidores tendem a utilizar-se somente das quatro operações para a tomada de decisão [...]" (p. 1303).

Além disso, a literatura é rica em textos relacionados a reflexões sobre os cursos de Licenciatura e os de Pedagogia - por exemplo, Gatti (2010), assim como em relação à formação Matemática do pedagogo - um exemplo, Almeida e Lima (2012). Mas, é desconhecido algum texto que responsabilize o pedagogo por não terminar o processo relacionado ao aprendizado das quatro operações fundamentais da matemática. Até porque, oficialmente, caberia ao professor dos anos finais um trabalho sistemático com os alunos para que os mesmos aperfeiçoassem o trabalho iniciado nos primeiros anos do Ensino Fundamental.

E, no que diz respeito, especificamente ao ensino do tema - quatro operações fundamentais da matemática (conteúdo e método) - no Ensino Superior não existe algum documento que indique a necessidade explicita do mesmo ser tratado em cursos de Licenciatura em Matemática. O que causa estranhamento, uma vez que o futuro professor de Matemática será responsável pela finalização do processo iniciado do primeiro ao quinto ano do Ensino Fundamental. Um espaço poderia ser criado durante o desenvolvimento da disciplina Prática de Ensino de Matemática com Estágio Supervisionado.

Voltando ao problema a ser discutido. O desenvolvimento de conceitos matemáticos, segundo o que foi apresentado anteriormente, é de extrema relevância no exercício da cidadania, bem como no desenvolvimento de habilidades cognitivas como fazer analogias, estimativas, classificações, generalizações, dentre outros. 
Mas, tal desenvolvimento deve ser realizado por meio de atividades que ultrapassem a simples memorização, favorecendo tanto a possibilidade de o sujeito conseguir viver em grupo de maneira satisfatória, bem como o desenvolvimento de estruturas psíquicas superiores.

Então, porque enfatizar a necessidade do aprendizado dos conceitos subjacentes às técnicas relacionadas às quatro operações fundamentais, se hoje, facilmente, pode-se ter acesso a calculadoras?

Primeiramente, existe um aprendizado implícito na utilização da calculadora; existem pessoas que não sabem utilizar tal ferramenta.

Segundo. A literatura e/ou documentos oficiais não incentivam, durante o processo de ensino aprendizagem de conteúdos matemáticos, a simples utilização da calculadora; "pegar e fazer o cálculo". Mas, utilizar esta ferramenta como recurso metodológico durante o desenvolvimento de atividades que visem o raciocínio lógico-matemático.

[...] constata-se que ela [calculadora] é um recurso útil para verificação de resultados, correção de erros, podendo ser um valioso instrumento de auto-avaliação. A calculadora favorece a busca e percepção de regularidades matemáticas e o desenvolvimento de estratégias de resolução de situaçõesproblema pois ela estimula a descoberta de estratégias e a investigação de hipóteses, uma vez que os alunos ganham tempo na execução dos cálculos. Assim elas podem ser utilizadas como eficiente recurso para promover a aprendizagem de processos cognitivos. Como exemplo de uma situação exploratória e de investigação que se tornaria imprópria sem o uso de calculadora, poder-se-ia imaginar um aluno sendo desafiado a descobrir e a interpretar os resultados que obtém quando divide um número sucessivamente por dois (se começar pelo 1 , obterá 0,$5 ; 0,25$; $0,125 ; 0,0625 ; 0,03125 ; 0,015625)$. Usando a calculadora, podem colocar sua atenção no que está acontecendo com os resultados, compará-los, levantar hipóteses e estabelecer relações entre eles, construindo significado para esses números. (BRASIL, 1998, p. 45)

Mas, quando um aluno já internalizou tais conceitos e se encontra numa etapa mais avançada de ensino a simples utilização faz sentido. 
Atitude, na maioria das vezes, vetada pelo professor de matemática e de outras disciplinas como Física e Química.

Terceiro. Deve-se ressaltar que o ensino e a aprendizagem das quatro operações não deveria se restringir, única e exclusivamente, às técnicas, para se chegar a algum resultado. Mas, possibilitar que o sujeito domine conceitos subjacentes ao processo porque, desta forma, exercita-se as funções psicológicas superiores e, consequentemente, ocorre a melhoria da qualidade dos processos cognitivos que, por sua vez, favorecem as novas aquisições conceituais e, assim, por diante.

Entretanto, nada disso acontece, se o professor de Matemática não possuir conhecimento suficiente para a elaboração de atividades que visem o aprendizado dos conceitos implícitos nos conteúdos previstos no currículo. Felicetti (2010) apresenta em seu artigo pesquisas que mostram que nem sempre a Matemática é considerada a disciplina mais dificil. Mas, sim, que a forma de trabalhar o currículo - ou seja, as experiências didático pedagógicas relacionadas a aprendizagem de matemática - é que propicia o enorme fracasso na aquisição de seus conteúdos. E mesmo com relação aos considerados "bons alunos" - que tiram notas satisfatórias - ocorre a dificuldade de compreensão quanto aos conceitos utilizados na resolução das tarefas.

Além disso, é de extrema importância uma estrutura que possibilite a implementação de novas metodologias, porque a organização que culminará na mediação do processo de ensino e de aprendizagem está sob responsabilidade do professor, mas, não depende só dele (LIBÂNEO; OLIVEIRA; TOSCHI, 2012). Um exemplo diz respeito a sala de informática. Existe um grande incentivo na utilização de Tecnologias de Informação e Comunicação (TIC's), mas é muito comum a não autorização por parte da gestão escolar para a utilização deste espaço pelo professor e seus alunos. São também conhecidos casos em que o professor autoriza a utilização do celular em sala de aula para 
implementar atividades que utilizem softwares, sendo que tal utilização é vetada por lei.

Por último vale destacar que o ensino de Matemática sempre apresentou problemas, como transcrição de Garnica (2008) do relato da Educadora Matemática Lourdes de La Rosa Onuchic apresentado no V Seminário Nacional de História da Matemática na UNESP de Rio Claro.

$\mathrm{O}$ que aconteceu neste século [século XX]? (...) tínhamos uma sociedade rural, que passou para uma sociedade industrial, que passou para uma sociedade de informação, e estamos numa sociedade de conhecimento. Com estas mudanças sociais, é claro que, se no começo pouca gente precisava saber matemática, depois [na sociedade industrial], exigindo técnicos, mais gente precisava e, posteriormente, com a informação, muito mais gente e, hoje, todos precisam. Então, [...] é claro que o homem se preocupou e ficou interessado em fazer reformas no ensino de matemática, visto que, de "não precisar quase saber" até "todos precisarem saber", muita coisa mudou. [...] Bem, com essas reformas de ensino, o que havia de início? "Se não sabem Matemática vamos ensinar a aprender Matemática". E como? Repete, repete, repete que aprende. E havia uma linha de pessoas que dizia: - "Faça repetir que aprendem". [...] Alguns aprenderam, mas a maioria não aprendia Matemática. Então, vamos pensar como fazer uma reforma jogando fora esta. Vamos pensar numa matemática com compreensão. Esta foi uma coisa que parecia promissora. Tinha Polya, Spitzer, falando numa Aritmética com compreensão, tinha no Brasil o Luís, Alberto Brasil, que falava em ensinar a partir de problemas com compreensão. Bem, quando isto parecia estar interessante, veio a Matemática Moderna. (GARNICA, 2008, p. 172)

As consequências do Movimento da Matemática Moderna para o ensino de Matemática foram decisivas na constituição da Educação Matemática como área de pesquisa. Fiorentini e Lorenzato (2009) associam três fatos para tanto,

O primeiro é atribuído à preocupação dos próprios matemáticos e de professores de Matemática sobre a qualidade da divulgação/socialização das idéias Matemáticas às novas gerações. [...] O segundo fato é atribuído à iniciativa das universidades européias, no final do século XIX em promover institucionalmente a formação de professores secundários. Isso contribuiu para o surgimento de especialistas universitários em Ensino de Matemática. O terceiro fato diz respeito aos estudos experimentais realizados por psicólogos americanos e europeus 
desde o início do século $\mathrm{XX}$, sobre o modo como as crianças aprendiam a matemática. No entanto, em nível internacional a pesquisa em Educação Matemática daria um salto significativo com o Movimento da Matemática Moderna (MMM), ocorrido nos anos de 1950 e 1960. (FIORENTINI; LORENZATO, 2009, p. 6)

Com o surgimento da Educação Matemática surgiram estudos sistematizados sobre o ensino e a aprendizagem da Matemática que perpassam por diversas linhas de pesquisa englobando desde a formação de professores à melhoria na qualidade de ensino por meio de metodologias diversificadas.

\section{Considerações finais}

Neste texto, utilizando experiências relacionadas às quatro operações matemáticas fundamentais discutiu-se a importância da aquisição de conceitos matemáticos no processo de desenvolvimento cognitivo. Observando que os conteúdos utilizados como mote fazem parte do currículo desde a criação da primeira escola brasileira (de ler, escrever e contar), construída no arraial do Pereira, assim que a armada de Tomé de Souza ancorou no recôncavo baiano, por volta de 1550. Além disso, ao longo dos anos, a importância de seu aprendizado foi reforçada por teóricos de outras áreas; Psicologia por exemplo. Portanto, trata-se de conteúdos curriculares que dificilmente deixaram de ser abordados no ambiente escolar. Mas, esta abordagem deve ser conceitual, não se limitando a simples resolução de "continhas". Uma vez apreendido o conceito esse conhecimento pode ser generalizado ou ainda transcendido para outras situações.

Mas, para que tal proposta seja implementada destaca-se a importância do professor no processo de ensino, considerando a mediação de aprendizagem como essencial na construção de conceitos científicos que possibilitem ao educando a melhoria na capacidade de entendimento de mundo. Portanto torna-se importante buscar a quebra 
na reprodução dos modelos didáticos internalizados ao longo do tempo. Sendo este um desafio a ser enfrentado por todos os professores (ensino básico e ensino superior). Porque é comum o professor formador apresentar métodos didáticos diferenciados e a sua prática não se constituir como um exemplo a ser seguido. Assim, não é rompido o ciclo de reprodução de modelos vivenciados que, muitas vezes, são do século XIX, apesar da produção científica a respeito e dos projetos de formação continuada.

\section{Referências}

ALMEIDA, Marlisa Bernardi de; LIMA, Maria das Graças de. Formação inicial de professores e o curso de Pedagogia: reflexões sobre a formação matemática. Ciênc. educ., Bauru, v. 18, n. 2, p. 451-468, 2012.

Disponivel em: http://www.scielo.br/pdf/ciedu/v18n2/a14v18n2.pdf. Acesso em: 12 dez. 2016.

BOGDAN, Robert C.; BIKLEN, Sari Knopp. Investigação qualitativa em educação: uma introdução a teoria e aos métodos. Porto- Portugal: Porto Editora, 1994.

BOLZAN, Doris Pires Vargas. Formação de professores: compartilhando e construindo conhecimentos. Porto Alegre: Mediação, 2002.

BRASIL, Ministério da Educação e do desporto. Parâmetros Curriculares Nacionais ( $5^{\mathrm{a}}$ a $8^{\mathrm{a}}$ séries): Matemática/ Secretaria de Educação

Fundamental. Brasília: MEC/SEF, 1998. Disponivel em:

<http://portal.mec.gov.br/seb/arquivos/pdf/matematica.pdf >

BRASIL. Ministério da Educação. Secretaria de Educação Média e Tecnológica. Parâmetros curriculares nacionais: ensino médio. Brasília: MEC/SEMTEC, 2000. V3. Disponivel em:

$<$ http://portal.mec.gov.br/seb/arquivos/pdf/blegais.pdf>

CARAÇA, Bento de Jesus. Conceitos fundamentais da Matemática.

Lisboa- Portugal; Editora Gradiva, 1998.

CHAUI, Marilena. Convite à Filosofia. São Paulo, Ed. Ática, 2000.

CLANDININ, D. Jean. Teacher education as narrative inquiry. In:

CLANDININ, D. Jean et al. (Ed.). Learning to teach, teaching to learn:

stories of collaboration in teacher education. Londres; Nova Iorque:

Teachers College; Columbia University Press, 1993.

CUNHA, Ana Cristina Barros da; ENUMO, Sônia Regina Fiorim; CANAL, Claudia Patrocínio Pedroza. Operacionalização de escala para análise de padrão de mediação materna: um estudo com díades mãe-criança com 
deficiência visual. Rev. Bras. Educ. Esp., Marília, v. 12, n. 3, p. 393-412, 2006. Disponivel em: <http://www.scielo.br/pdf/rbee/v12n3/06.pdf>. DA SILVEIRA, Marisa Rosâni Abreu. Linguagem matemática e comunicação: Um enfoque interdisciplinar. Amazônia: Revista de Educação em Ciências e Matemáticas, v. 6, p. 81-92, 2010. Disponível em: $<$ http://www.periodicos.ufpa.br/index.php/revistaamazonia/article/vie $\mathrm{w} / 1705>$

DE AZEVÊDO, Maria Alves; DO RÊGO, Rogéria Gaudencio. Linguagem e matemática: a importância dos diferentes registros semióticos. Revista Temas em Educação, v. 25, p. 158-171, 2016. Disponivel em: <http:// periodicos.ufpb.br/index.php/rteo/article/view/25270> DE LIMA DIAS, Maria Sara; KAFROUNI, Roberta; BALTAZAR, Camilla Silva; STOCKI, Juliana. A formação dos conceitos em Vigotski: replicando um experimento. Psicologia Escolar e Educacional, v. 18, n. 3, 2014. Disponivel em: <http://www.scielo.br/pdf/pee/v18n3/1413-8557pee-18-03-0493.pdf $>$

FELICETTI, Vera Lucia. Linguagem do professor: aspecto central no ensino da Matemática. PBL 2010 Congresso Internacional. São Paulo, Brasil, 2010. Disponivel em:

<http://each.uspnet.usp.br/pbl2010/trabs/trabalhos/TC0089-1.pdf> FIORENTINI, Dario; LORENZATO, Sergio. Investigação em educação matemática: percursos teóricos e metodológicos. Campinas-SP: Autores Associados, 2009.

FREITAS, M. T. M.; FIORENTINI, D. As possibilidades formativas e investigativas da narrativa em educação matemática. Horizontes, São Francisco, v. 25, n. 1, p. 63-71, jan./jun., 2007. GARNICA, Antonio Vicente Marafioti. Resgatando oralidades para a história da Matemática e da Educação Matemática brasileiras: o Movimento Matemática Moderna p.163-217. Zetetike, Campinas, SP, v. 16, n. 2, out. 2009. ISSN 21761744. Disponivel em:

$<$ https://periodicos.sbu.unicamp.br/ojs/index.php/zetetike/article/view /8646895>.

GATTI, Bernardete A. Formação de professores no Brasil: características e problemas. Educ. Soc., Campinas, v. 31,n. 113,p. 1355-1379, Dec. 2010 . Disponivel em: <http://www.scielo.br/pdf/es/v31n113/16.pdf>. Acesso em: 31 Mar. 2016.

GÓES, Maria Cecília Rafael; CRUZ, Maria Nazaré. Sentido, significado e conceito: notas sobre as contribuições de Lev Vigotski. Pro-posições, v. 17, n. 2, p. 31-45, 2006. Disponivel em:

$<$ https://periodicos.sbu.unicamp.br/ojs/index.php/proposic/article/vie $\mathrm{w} / 8643627>$

KISTEMANN JR., Marco Aurélio; LINS, Romulo Campos. Enquanto isso na Sociedade de Consumo Líquido-Moderna: a produção de significados 
e a tomada de decisão de individuos-consumidores. Bolema, Rio Claro, v. 28, n. 50, p.1303-1326, dez., 2014. Disponível em:

<http:/ / www.scielo.br/pdf/bolema/v28n50/ 1980-4415-bolema-28-501303.pdf>. Acesso em: 30 fev 2017.

LIBÂNEO, José Carlos; OLIVEIRA, João Ferreira de; TOSCHI, Mirza

Seabra. Educação Escola: Políticas, Estrutura e Organização. São Paulo: Cortez,2012.

LORENSATTI, Edi Jussara Candido. Linguagem matemática e Língua Portuguesa: diálogo necessário na resolução de problemas matemáticos. CONJECTURA: filosofia e educação, v. 14, n. 2, 2009. Disponivel em:

<https://www.ucs.br/site/midia/arquivos/linguagem.pdf> MARTINS, Lígia Márcia. Os fundamentos psicológicos da pedagogia histórico-crítica e os fundamentos pedagógicos da psicologia históricocultural. Germinal: Marxismo e Educação em Debate, Salvador, v. 5, n. 2, p. 130-143, dez. 2013. Disponível em:

https://portalseer.ufba.br/index.php/revistagerminal/article/view/9705 MIGUEL, José Carlos. O ensino de matemática na perspectiva da formação de conceitos: implicações teórico-metodológicas. Núcleos de Ensino-PROGRAD-UNESP, v. 1, p. 375-394, 2011. Disponivel em: http:/ / www.unesp.br/portal\#! / prograd/e-livros-prograd/ MORAES, Silvia Pereira Gonzaga de et al. Avaliação do processo de ensino e aprendizagem em Matemática: contribuições da teoria históricocultural. Bolema, v. 22, n. 33, p. 97-116, 2009. Disponivel em: <http://www.periodicos.rc.biblioteca.unesp.br/index.php/bolema/issue /view/778>

MOYSÉS, L. Aplicações de Vigotski à Educação Matemática. $11^{\mathrm{a}} \mathrm{ed}$. Campinas: Papirus, 2010.

NOGUEIRA, Maria Clélia Ignatius. Pesquisas atuais sobre a construção do conceito de número: para além de Piaget?. Educar em Revista, n. 1, 2011. Disponivel em: <http://www.scielo.br/pdf/er/nse1/08.pdf> OLIVEIRA, Marta Kohl de. Vigotski e o processo de formação de conceitos. In: Piaget, Vigotski, Wallon - Teorias psicogenéticas em discussão. São Paulo: Summus, 1992.

SFORNI, Marta Sueli de Faria. Aprendizagem conceitual e organização do ensino: contribuições da teoria da atividade. Araraquara: JM Editora, 2004

TASSONI, Elvira Cristina Martins. Afetividade e aprendizagem: a relação professor-aluno. Reunião anual da ANPED, 2000. Disponível em: <http://www.anped.org.br/reunioes/23/textos/2019t.PDF>. VYGOTSKY, Lev Semyonovich. A formação social da mente - o desenvolvimento dos processos psicológicos superiores. São Paulo: Martins Fontes, 1988. . Pensamento e linguagem. 3. ed. São Paulo: M. Fontes, 1991. 
VYGOTSKY, Lev Semyonovich; LURIA, Alexander Romanovich; LEONTIEV, Alexis Nikolaevich. Linguagem, desenvolvimento e aprendizagem. 2. ed. São Paulo: Ícone - Editora da Universidade de São Paulo, 1988. 